\title{
Health and well-being of homeless veterans participating in transitional and supported employment: Six-month outcomes
}

\author{
Meaghan Leddy, PhD $;^{1-2 *}$ Elina Stefanovics, PhD; ${ }^{2}$ Robert Rosenheck, $\mathrm{MD}^{1-2}$ \\ ${ }^{1}$ Department of Veterans Affairs Connecticut Health Care System, West Haven, CT; ${ }^{2}$ Yale University School of Medi- \\ cine, New Haven, CT
}

\begin{abstract}
Supported employment, specifically individual placement and support (IPS), improves competitive employment $(\mathrm{CE})$ rates for individuals with serious mental illness, but has not shown greater improvement in non-vocational outcomes than other rehabilitation approaches. The Department of Veterans Affairs offers two types of vocational services, IPS and transitional work experience (TWE), but no study has compared the effectiveness of these approaches. This secondary analysis of data from a study of homeless veterans compared 6 mo improvement in diverse outcomes for five employment patterns: never worked, worked only in TWE, worked in TWE followed by CE, worked in CE without IPS, and worked in CE with IPS referral. Veterans referred to IPS were more likely to be competitively employed. Those who worked in CE (whether following TWE or with or without IPS referral) showed the greatest increase in days worked, employment income, and total income and the greatest decrease in public support income when compared with those who worked only in TWE or not at all. Veterans in TWE showed the greatest increase in residential treatment days, but there were no other differences in nonvocational outcomes between groups. There are multiple paths to $\mathrm{CE}$, but few differences in non-vocational outcomes across employment experiences.
\end{abstract}

Key words: compensated work therapy, employment, homeless, individual placement and support, recovery, severe mental illness, substance use, supported employment, transitional work experience, veterans.

\section{INTRODUCTION}

One of the most serious consequences of severe mental illness (SMI) is that it impedes participation in employment [1-3]. Diverse approaches have been used to facilitate employment for individuals diagnosed with SMI, including sheltered workshops, skills training, clubhouses, and supported employment (SE) [4]. Some of these programs specifically seek to foster competitive employment (CE) (i.e., jobs in the competitive economy that are open to all workers and pay standard wages) and

\footnotetext{
Abbreviations: $\mathrm{ANCOVA}=$ analysis of covariance, $\mathrm{ASI}=$ Addiction Severity Index, $\mathrm{CE}=$ competitive employment, $\mathrm{CWT}=$ compensated work therapy, DPA $=$ diversified placement approach, IPS = individual placement and support, IRB = institutional review board, MCS $=$ mental health composite score, $\mathrm{PCS}=$ physical health composite score, PTSD $=$ posttraumatic stress disorder, SCL-30 $=33$ items from Symptom Checklist 90, SE $=$ supported employment, SF-12 $=12$-Item Short Form Health Survey, SMI = severe mental illness, TEPS = therapeutic employment placement and support, TWE $=$ transitional work experience, $\mathrm{VA}=$ Department of Veterans Affairs. *Address all correspondence to Meaghan Leddy, PhD; Department of Veterans Affairs Connecticut Healthcare System, 950 Campbell Ave, BIdg 15, Rm 127, West Haven, CT 06516; 203-444-6191. Email: meaghan.leddy@vale.edu http://dx.doi.org/10.1682/JRRD.2013.01.0011
} 
some seek non-CE (i.e., protected jobs that are "owned" by programs that set their own, often reduced, wages and may be less demanding and more acceptable to clients) [5-7].

The Department of Veterans Affairs (VA) has offered therapeutic work programs through its compensated work therapy (CWT) program since the 1970s. Initially, veterans were offered employment opportunities in sheltered workshops, but more recently the program has emphasized transitional work experience (TWE) offering non-CE in both therapeutically managed VA [8] jobs and jobs with community employers [8-10]. In December 2003, as a result of new legislation [11], SE services following the individual placement and support (IPS) model began to be offered along with TWE within VA's CWT programs.

\section{Supported Employment}

The IPS model of SE [12-16] emphasizes rapid job placement, competitive jobs, ongoing support without a time limit, client choice of jobs, integration of vocational support and clinical care, and openness to all who want to work [17]. Clinical trials have shown IPS to be associated with higher $\mathrm{CE}$ rates, shorter time to entering $\mathrm{CE}$, greater numbers of hours worked per week, and more weeks worked per year among individuals diagnosed with SMI [13,16-26] and, most recently, among veterans with posttraumatic stress disorder (PTSD) [27]. The program is most effective when fidelity to the model is high [28-30].

In addition to employment-related outcomes, many researchers and program planners have hoped nonvocational outcomes would also improve through vocational programs. Those who obtain CE via IPS have been shown to have improved self-esteem, quality of life, social inclusion, and psychiatric symptoms [20,31-33], and improvements have been shown to be maintained during follow-up, for as many as $12 \mathrm{yr}$ [7,34]. Although IPS has been associated with improvements in some nonvocational outcomes in observational outcome studies, these improvements have not been greater than those demonstrated by other rehabilitation programs when evaluated in randomized trials [33,35-38]. Several other studies that favored IPS with regard to vocational outcomes failed to find greater improvement in non-vocational outcomes [27,37].

Nor have advantages been found for IPS in studies that specifically evaluated psychiatric symptoms [39-
42], quality of life [39,41-42], self-esteem [40], global functioning [40-42], relapses [41], coping [41], social support [42], or substance misuse [42]. When differences on non-vocational outcomes have been identified, they have been small [20] or possibly due to baseline differences and resultant regression to the mean [42]. Nevertheless, some suggest that IPS can positively affect nonvocational outcomes because of its association with increased rates of $\mathrm{CE}$, which has been associated, in turn, with improved non-vocational outcomes [43].

\section{Transitional Work Experience}

When compared to traditional job placement services, VA's TWE program has been associated with an increased likelihood of engaging in paid activity, a greater number of hours and weeks worked, and higher income [44]. Groups did not differ, however, in more specifically improving CE. In an earlier randomized trial, Kashner and colleagues demonstrated that when compared to no vocational intervention, TWE was associated with greater reductions in substance use, fewer periods of homelessness and incarceration, and less of a decline in physical health [9]. TWE has also been associated with decreased utilization of inpatient care and increased outpatient care for individuals with SMI or those who are dually diagnosed [45].

As of yet, there has been no direct comparison of IPS and TWE or of either with the sequence of CWT followed by $\mathrm{CE}$ on either vocational or non-vocational outcomes. However, VA TWE (i.e., non-CE) has been described [44] as similar to Koop and colleagues' [46] diversified placement approach (DPA), which has been compared with IPS [47-48]. DPA has been associated with lower rates of $\mathrm{CE}$, fewer total weeks of competitive work, and less income earned when compared with IPS. However, when only individuals who had obtained at least one job were examined, these differences were no longer significant and DPA had superior outcomes on total number of weeks of paid employment [47].

\section{Current Study}

This observational study is the first to compare vocational and non-vocational outcomes between VA's TWE and IPS programs and for the sequence of TWE followed by CE. This is a secondary analysis of data from a previous VA demonstration program, the therapeutic employment placement and support (TEPS). The TEPS study demonstrated that for homeless veterans, many of whom 
had primary substance use disorders rather than SMI, IPS was associated with more days of $\mathrm{CE}$ and fewer days of homelessness than standard VA care, but showed no differences on other outcomes [49]. The original study compared IPS and treatment as usual in an intention-to-treat analysis, but because both cohorts in the demonstration had access to TWE services, the data set provides the opportunity to conduct an observational analysis in which data from the cohorts are combined and changes in employment and other outcomes from the time of program entry to 6 mo are compared under five employment conditions: (1) never worked, (2) worked only in TWE, (3) worked in TWE followed by CE (either with or without IPS), (4) worked only in CE without IPS, and (5) worked only in CE with IPS referral. Individuals who worked first in CE and then in TWE were excluded because of small numbers, as were those with incomplete followup data.

The comparison of IPS and TWE is of particular importance in the VA context given that TWE has a long history within VA and that IPS has been implemented only over the past decade. We hypothesized that improvement on non-vocational outcomes would be greater for all work conditions than not working at all, but that non-vocational outcomes would not differ among employment conditions.

\section{METHODS}

In January 2000, funds were allocated for nine VA medical centers to hire and train employment specialists to provide IPS services to homeless veterans with psychiatric or substance use disorders. Veterans were considered eligible if they met all three of the following criteria:

1. Veteran was homeless and not receiving VA health services. Participants were considered to be homeless if they had slept in a shelter or on the street in the past $90 \mathrm{~d}$.

2. Veteran expressed interest in seeking CE. Veterans were deemed interested in CE if they answered in the affirmative when asked, "Are you interested in working for pay in the community-somewhere other than at the VA?"

3. Veteran was diagnosed with a psychiatric disability and/or substance use problem.

Beginning on January 1, 2001, eligible veterans were recruited at each site before the implementation of IPS (cohort $1, n=308$ ) and were offered standard VA care (including TWE). They were subsequently assessed by an independent evaluation assistant every 3 mo for up to 2 yr. After the nine sites had hired and trained employment specialists (as described by Rosenheck and Mares [49]), a second group of homeless veterans, cohort 2 ( $n=$ 322 ), was recruited and offered both IPS and standard care (including TWE). They were assessed in the same way over the next 2 yr. No participants in cohort 1 participated in cohort 2. Follow-up data collection continued through March 2005.

Data were collected by independent, trained research assistants, and efforts were made to collect outcome data in the original study on all veterans regardless of the VA rehabilitation services they were receiving. Veterans gave written informed consent to participate in the study and for employment specialists to communicate with employers. Participants received $\$ 10.00$ for each interview they completed. Original institutional review board (IRB) approval was obtained at the authors' parent institution and at each of the nine participating VA facilities. Overall follow-up rates across all time points averaged 70 percent $(n=1,730$ interviews) for cohort 1 and 72 percent $(n=$ 1,858 interviews) for cohort 2.

In the present study, data from the two cohorts were combined and changes in employment and other outcomes from the time of program entry to 6 mo follow-up were compared among homeless veterans $(n=440)$ in five groups defined by their patterns of employment during the first 6 mo of program participation: not working at any time, working only in TWE, working in TWE followed by CE, working only in CE before IPS was available, and working only in CE after IPS was available (Figure). Individuals who worked in other patterns $(n=$ 14 ) or who had missing data from the first or second followup assessments were excluded $(n=176)$. The analysis was limited to the first 6 mo of program participation to limit both the amount of missing follow-up data and the potential number of combinations and permutations of work experiences (Figure).

\section{Measures}

\section{Employment Status}

Employment was assessed by three measures representing the number of days in the past 30 of (1) CE, (2) nonCE (e.g., TWE in VA's CWT program), (3) casual or volunteer work, and (4) any type of employment (i.e., the 


\section{Total Sample}

Cohort 1

Competitive Employment when IPS not available
Cohort 2

Competitive employment with referral to IPS

Transitional Work Experience (TWE) only

\section{No Work}

Figure.

Employment conditions examined over 6 mo in this study. IPS = individual placement and support.

sum of the previous three measures). Employment data were based on client interviews.

\section{Health Status}

Diagnoses were based on clinical assessments by homeless outreach staff. Subjective distress was measured with 33 items from the Symptom Checklist 90 (SCL-30) (range 0-4) [50]. Alcohol and substance use problems were assessed by using composite scores from the Addiction Severity Index (ASI) (range 0-1) [51]. The 12-item Short Form Health Survey (SF-12) [52] was used to assess mental (mental health composite score [MCS]) and physical health status (physical health composite score $[\mathrm{PCS}])($ range $=$ standardized scores $\times 10)$.

\section{Community Adjustment and Housing Status}

Housing status was measured by questions concerning sleeping arrangements during the previous $90 \mathrm{~d}$ in each of 12 types of places and used to calculate days of independent housing (whether in their own place or with others), days homeless, and days in institutions (hospitals or time-limited transitional residences).

\section{Attitudes Toward Employment, Self-Esteem, and Quality of Life}

Attitudes toward work were assessed using a 21-item measure used in the Social Security Administration's Project NetWork [53]. A factor analysis of these 21 items (varimax rotation) produced a 5-component measure reflecting attitudes toward work that can be summarized as "I can't work," "I want to work," "Work helps me cope with problems," "I don't like the jobs I get," and "Others expect me to work" [54]. Self-esteem was assessed with the Rosenberg Self-Esteem measure [55], and quality of life was measured by the single summary item in the Lehman Quality of Life Interview [56].

\section{Analysis}

For the current study, both cohorts were combined to create one sample $(n=588)$. Six-month follow-up data were available for 440 veterans who fit into one of the five work patterns previously described.

First, baseline sociodemographic variables and clinical characteristics that were significantly different (at $p<$ 0.05) across employment patterns were identified because they could potentially confound outcome analysis (Tables 1-2). These variables were included as covariates to adjust for potentially confounding baseline characteristics in the subsequent analysis of covariance (ANCOVA) of 6 mo changes in outcome measures from the time of program entry across the five work patterns. ANCOVAs of change also controlled for the baseline value of the dependent variable in each. Least square (adjusted) means were compared between pairs of conditions if the overall difference across work patterns was significant at $p<0.01$, selected as the alpha level to adjust for multiple comparisons across many (often related) outcomes.

VA TWE programs are often linked with transitional residences, domiciliaries, and other VA residential programs, and preliminary analysis confirmed that veterans in the TWE-only group spent substantially more days residing in institutional settings than the other groups. To adjust for this potentially confounding variable, the number of days in VA residential or inpatient treatment was also included as a covariate in the ANCOVAs of nonhousing 
Table 1.

Baseline veteran characteristics by work pattern category. Data shown as number (\%).

\begin{tabular}{|c|c|c|c|c|c|c|c|c|}
\hline Variable & $\begin{array}{l}\text { No Work } \\
(n=100)\end{array}$ & $\begin{array}{l}\text { TWE Only } \\
(n=96)\end{array}$ & $\begin{array}{l}\text { TWE then CE } \\
\text { or IPS }(n=30)\end{array}$ & $\begin{array}{l}\text { CE Without } \\
\text { IPS Only: } \\
\text { Cohort } 1 \\
(n=58)\end{array}$ & $\begin{array}{c}\text { IPS Referral } \\
\text { Only: Cohort } 2 \\
(n=156)\end{array}$ & $\chi^{2}$ & $d f$ & $p$-Value \\
\hline \multicolumn{9}{|l|}{ Baseline Demographic } \\
\hline Male & $86(86.00)$ & $90(94.74)$ & $28(93.33)$ & $55(94.83)$ & $142(91.03)$ & 6.06 & 4 & 0.20 \\
\hline Married & $4(4.00)$ & $2(2.11)$ & $2(6.67)$ & $0(0.00)$ & $14(8.97)$ & 10.28 & 4 & 0.04 \\
\hline White & $41(41.00)$ & $34(35.42)$ & $14(46.67)$ & $18(31.03)$ & $64(41.29)$ & 3.32 & 4 & 0.51 \\
\hline Enlisted & $98(98.00)$ & $96(100.00)$ & $30(100.00)$ & $58(100.00)$ & $155(99.36)$ & 3.83 & 4 & 0.43 \\
\hline Honorable Discharge & $89(89.00)$ & $83(86.46)$ & $24(80.00)$ & $50(86.21)$ & $134(85.90)$ & 1.65 & 4 & 0.80 \\
\hline \multicolumn{9}{|l|}{ Baseline Financial } \\
\hline $\begin{array}{l}\text { Service-Connected } \\
\text { Disability }\end{array}$ & $16(16.00)$ & $11(11.46)$ & $5(16.67)$ & $4(6.90)$ & $17(10.97)$ & 3.73 & 4 & 0.44 \\
\hline VA Pension & $2(2.00)$ & $2(2.08)$ & $0(0.00)$ & $2(3.45)$ & $0(0.00)$ & 5.09 & 4 & 0.29 \\
\hline \multicolumn{9}{|l|}{ Disability Status } \\
\hline No Intent to Apply & $38(38.00)$ & $42(43.75)$ & $20(66.67)$ & $32(55.17)$ & $92(58.97)$ & 16.10 & 4 & 0.003 \\
\hline Applied/Applying & $43(43.00)$ & $43(44.79)$ & $5(16.67)$ & $21(36.21)$ & $44(28.21)$ & 14.37 & 4 & 0.006 \\
\hline Receiving & $38(38.00)$ & $42(43.75)$ & $20(66.67)$ & $32(57.14)$ & $92(59.74)$ & 17.3 & 4 & 0.002 \\
\hline \multicolumn{9}{|l|}{ Baseline Clinical } \\
\hline Schizophrenia & $10(10.00)$ & $5(5.21)$ & $0(0.00)$ & $5(8.62)$ & $10(6.45)$ & 4.50 & 4 & 0.34 \\
\hline Mood Disorder & $36(36.00)$ & $41(42.71)$ & $12(40.00)$ & $17(29.31)$ & $49(31.61)$ & 4.45 & 4 & 0.35 \\
\hline PTSD & $8(8.00)$ & $5(5.21)$ & $7(23.33)$ & $2(3.45)$ & $4(2.58)$ & 20.93 & 4 & $<0.001$ \\
\hline Alcohol Abuse & $63(63.00)$ & $67(69.79)$ & $19(63.33)$ & $32(55.17)$ & $97(62.58)$ & 3.43 & 4 & 0.49 \\
\hline Drug Abuse & $53(53.00)$ & $58(60.42)$ & $21(70.00)$ & $36(62.07)$ & $92(59.35)$ & 3.30 & 4 & 0.51 \\
\hline $\begin{array}{l}\text { No Mental Health } \\
\text { Diagnosis }\end{array}$ & $4(4.00)$ & $3(3.13)$ & $1(3.33)$ & $6(10.34)$ & $7(4.52)$ & 4.82 & 4 & 0.31 \\
\hline $\begin{array}{l}\text { Other Mental Health } \\
\text { Diagnosis }\end{array}$ & $30(30.00)$ & $32(33.33)$ & $7(23.33)$ & $16(27.59)$ & $51(32.90)$ & 1.70 & 4 & 0.79 \\
\hline Dual Diagnosis & $45(45.00)$ & $54(56.25)$ & $19(63.33)$ & $29(50.00)$ & $63(40.65)$ & 9.25 & 4 & 0.06 \\
\hline
\end{tabular}

outcomes (i.e., this variable was not used as a covariate when comparing groups on housing outcomes). The significance level for paired comparisons was also set at $p<$ 0.01 because of the multiple planned comparisons. Data management and statistical analysis was performed by using SAS $^{\circledR}$ version 9.2 (SAS Institute; Cary, North Carolina).

\section{RESULTS}

The initial bivariate analyses identified baseline measures that were significantly associated with the employment classification (Tables 1-2). Significant differences were observed in a limited number of variables including marital status, application for or receipt of VA or non-VA disability benefits, PTSD diagnosis, age, days homeless, baseline days of employment, self-esteem, and two measures of psychiatric symptoms. The strongest effects $(p<$ $0.01)$ showed veterans who worked were less interested in applying for disability at baseline, less likely to have a diagnosis of PTSD, were younger, had higher selfesteem, were working more days at the time of program entry, and had lower psychiatric symptom scores.

It is notable, first of all, that there were highly significant differences in the work patterns before and after IPS became available $\left(\chi^{2}(3)=45.0, p<0.001\right)$. In cohort 1 , 30.7 percent worked in CE, as compared with 62.2 percent in cohort 2 (when IPS was available); 9.0 percent worked in TWE and then CE in cohort 1, as compared with 5.2 percent in cohort $2 ; 32.3$ percent worked only in TWE in cohort 1 , as compared with 13.9 percent in cohort 2; and 28.0 percent did not work at all, as compared 
JRRD, Volume 51, Number 1, 2014

Table 2.

Baseline variables associated with each employment pattern (least square [LS] means).

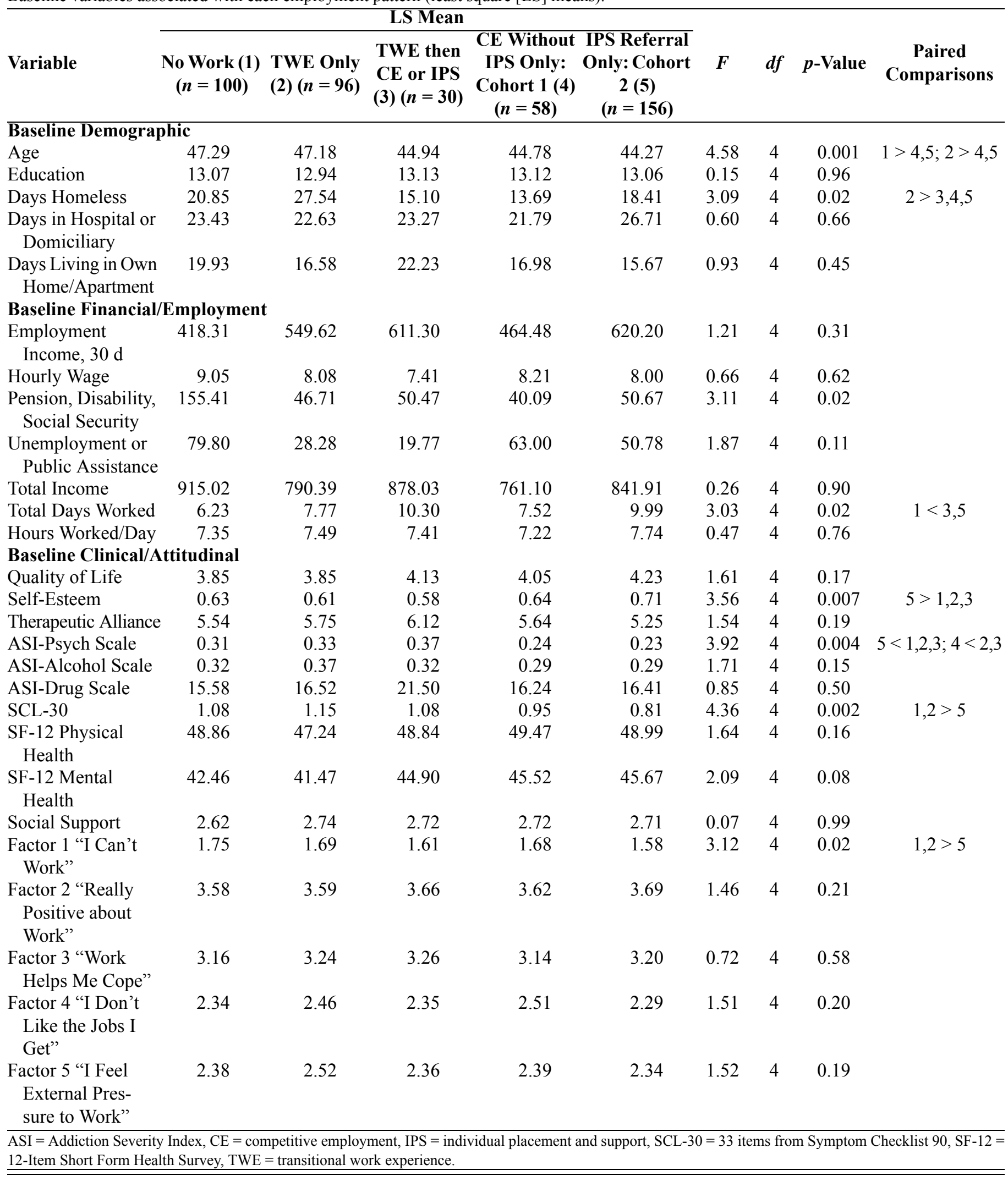


with 18.7 percent in cohort 2 . Thus, 39.7 percent worked in $\mathrm{CE}$ at some time during the first 6 mo of cohort 1 , as compared with 67.3 percent in cohort 2 .

\section{Employment-Related Outcomes}

When looking at change in the number of days worked from baseline to 6 mo follow-up, those in TWE only had a significantly smaller increase in days worked than the other three groups that were employed at all (all $p<0.001$ ) (Table 3). Not surprisingly, by definition, those who had not worked in the previous 6 mo had a significantly poorer outcome on days worked compared with all other groups (all $p<0.001$ ).

Those who had gained work through TWE only had increases in public support income, which was significantly different from those in CE with IPS referral, who had relative reductions in public support income $(p=$ 0.009). Those in the no work group also showed increased receipt of public support income, which was significantly different from the TWE then CE $(p=$ $0.002)$, CE without IPS $(p=0.0002)$, and CE with IPS referral $(p<0.001)$ groups, who showed reduced public assistance income. Those in no work did not differ from TWE only in this regard $(p=0.14)$.

Veterans who had had any CE (TWE then CE, CE without IPS, or CE with IPS referral) during the 6 mo period had superior outcomes in work-related income (all $p<0.004)$ and total income (all $p<0.001$ ) when compared with those who had only worked TWE or those who had not worked at all. Again, the TWE only and no work groups did not differ.

\section{Housing-Related Outcomes}

As expected, the TWE only group showed a far greater increase in days living in institutions (domiciliaries, transitional residences, or hospitals) than did those who worked through IPS $(p<0.001)$ and those who did not work $(p<0.001$; Table 3). The no work group showed a significantly smaller decline in days living with others than CE with IPS referral $(p=0.004)$ and CE without IPS $(p<0.008)$, but there were no differences in days homeless or days living independently in one's own place.

\section{Health, Wellness, Self-Esteem, and Quality of Life}

There were no significant differences between the five groups with regard to clinical outcomes as measured by the ASI-Alcohol, ASI-Drug, or ASI-Psych, the SCL-
30, SF-12 MCS or PCS, quality of life, self-esteem, or social support measures.

\section{Employment Attitude Changes}

There was only one significant difference with regard to changes in positive work attitudes or beliefs about work. With regard to the belief "I want to work," the No Work group had a significantly larger decline in this attitude than did CE without IPS $(p<0.001)$.

\section{DISCUSSION}

This secondary analysis compared the magnitude of 6 mo change in vocational and non-vocational outcomes associated with five employment patterns: not working, working only in TWE, working in TWE followed by CE (either with or without IPS referral), CE without IPS, and CE with IPS referral. IPS was associated with increased rates of achieving CE (39\% in cohort 1 vs $67 \%$ in cohort 2 ), which has been robustly demonstrated in the literature on people with SMI [16-19]. However, IPS was not associated with universally superior outcomes on other employment-related variables when compared with other competitive work patterns (i.e., TWE then CE or CE without IPS). These results are similar to other studies that have found that IPS influences achievement of CE, but does not necessarily improve employment of any kind or employment income more than other approaches [47].

Not surprisingly, having had any CE, regardless of how it was achieved, was associated with better employment-related outcomes than non-CE or no employment. For example, having had any $\mathrm{CE}$ was associated with greater number of days worked and greater increases in total and work income than TWE or no work. Reciprocally, public support income increased most among those who did not work or who worked in TWE, though those receiving public support payments may have less incentive to work or may fear it could lead to reduction or loss of public support income [7,57-59].

Benefits did not extend beyond work and financial domains. There were relatively few differences between the five groups with regard to health, wellness, quality of life, self-esteem, and housing outcomes. This corroborates previous reports that the benefits of vocational services are limited to vocational outcomes [33,35-38].

Of particular interest was the comparison of TWE and IPS, given that VA currently offers both these vocational 
JRRD, Volume 51, Number 1, 2014

Table 3.

Paired comparisons among five employment patterns.

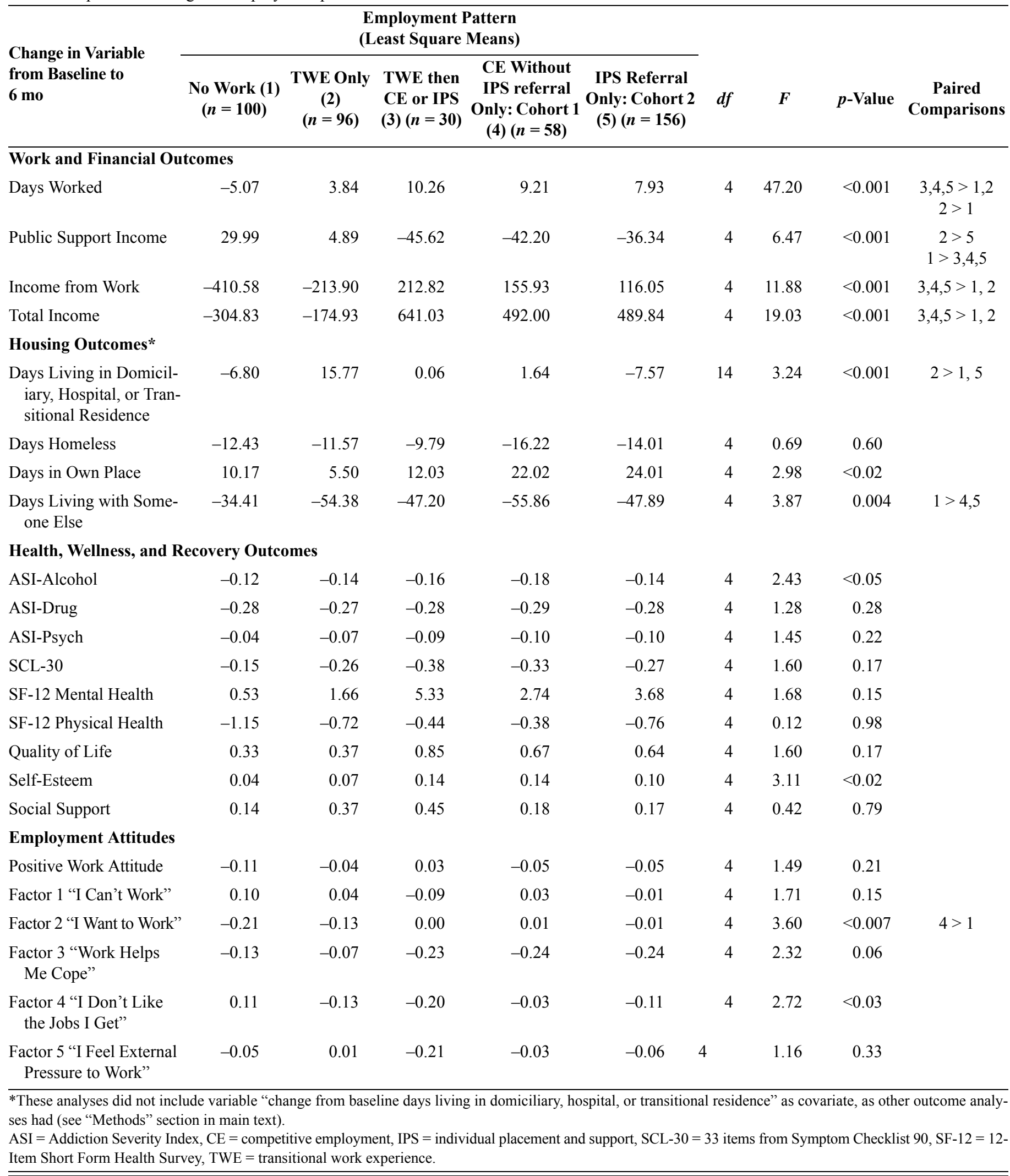


services (although, in contrast to the study described here, IPS in VA is limited to those with SMI). There were baseline differences between those who enrolled in TWE only and those who achieved CE with referral to IPS. For example, individuals in the CE with IPS referral group were younger, had less severe mental health symptoms, reported less subjective distress, had been homeless for fewer days, had higher levels of self-esteem, and less strongly held the belief "I can't work" than others.

When adjustment was made for these baseline differences at 6 mo follow-up, IPS was superior to TWE with regard to all employment and financial outcomes, such as the number of days worked, income from work, and total income. Those in TWE had more days living in a domiciliary, hospital, or transitional residence, as expected given that many TWE programs are affiliated with these types of residential settings. The two groups did not differ on any other non-vocational outcomes. Also notable is that the TWE only and CE with IPS referral groups did not differ on work attitudes at 6 mo follow-up, indicating that these two types of vocational rehabilitation did not differentially affect their attitudes toward work and, more specifically, their feeling external pressure to work. This last finding highlights that the additional support provided by vocational programs (e.g., vocational counselors) is not viewed as a source of pressure to pursue employment beyond their personal preferences.

Several methodological limitations deserve comment. Given that this study is observational in nature, there is inherent causal ambiguity with regard to outcomes. The associational nature of the data does not allow unambiguous determination of whether employment status influences clinical outcomes or whether improved clinical outcomes lead to better employment status. However, in the absence of significant associations, one can reasonably conclude that neither is the case. Further, the 6 mo follow-up period is a relatively brief time compared with some studies and may not have been long enough for individuals to have engaged in enough work to influence their non-vocational status; it has been demonstrated that it is steady work, rather than mere exposure to work (i.e., $1 \mathrm{~d}$ or more) that influences outcomes $[31-32,60]$. However, this was the most manageable time frame for which we could calculate the work pattern for each individual (e.g., working in TWE first, followed by CE).

In addition, these two nonrandomized cohorts were combined to create one sample, despite the fact that cohort 1 preceded cohort 2 , resulting in a potential historical confound. However, given that the literature suggests that IPS is superior in fostering CE, the current context would make conducting a randomized clinical trial difficult, given the perceived lack of equipoise. It should also be noted that IPS does not have a large evidence base for improving employment in a largely substance using, homeless population and research has primarily focused on clients with SMI. There is some evidence that IPS helps individuals with co-occurring mental health and substance use diagnoses achieve better employment outcomes than other vocational services [60-61]; however, IPS may be less advantageous for the population studied here, offering a possible explanation for the lack of significant findings in non-vocational outcomes between the groups. These findings may have also been influenced by the 70-72 percent follow-up rates, leading to a potential selection bias; differences may have gone unmeasured because of attrition, which may have confounded the comparison of groups.

The lack of significant differences in non-vocational outcomes may also have reflected less than optimal fidelity to the IPS model. While fidelity was rated as "adequate" at most sites [49], adequate implementation may not have been enough to demonstrate the differences in outcomes between IPS and other employment groups [62], especially given that outcomes have been noted to show most improvement when IPS fidelity is high [2830]. Finally, while there is some circularity in comparing employment outcomes among groups with different predefined work patterns (e.g., comparing no work and IPS on number of days worked), information is gained from examining employment outcomes among the four groups that were characterized by employment, such as comparing number of days worked for those in TWE only and CE with IPS referral.

Despite these limitations, this study is the first to compare the outcomes of individuals enrolled in both VA vocational programs, IPS and TWE, finding few differences between them and further demonstrating the distinctive role of IPS in fostering CE but not improvements in non-vocational outcomes.

\section{CONCLUSIONS}

In this study, IPS was, and has previously been, robustly associated with increased rates of achieving CE [16-19]. However, IPS has not been generally found to 
be associated with superior outcomes on other employmentrelated variables, such as employment income, when compared with other competitive work patterns or rehabilitative approaches [47]. Whether or not it was obtained via IPS, CE was associated with better employment-related outcomes than non-CE or no employment. Benefits were not found to carry over to non-vocational outcomes, and it seems that the benefits of vocational services are limited to achieving employment [33,3538]. Specifically relevant to the VA context is the comparison of IPS and TWE. IPS was superior to TWE with regard to vocational outcomes, though the two did not differ on non-vocational outcomes or attitudes towards working. There are several reasons this may have occurred: IPS may be less advantageous for Veterans experiencing homelessness and predominantly with substance use problems, fidelity to the IPS model may have been less than optimal, and attrition may have attenuated observed benefits. This study is the first to compare the outcomes of VA's two vocational programs, IPS and TWE, and provides further evidence demonstrating that IPS fosters engagement in CE but does not result in improvements in non-vocational domains.

\section{ACKNOWLEDGMENTS}

\author{
Author Contributions: \\ Study concept and design: M. Leddy, E. Stefanovics, R. Rosenheck. \\ Statistical analysis: E. Stefanovics, R. Rosenheck. \\ Interpretation of data: E. Stefanovics, R. Rosenheck, M. Leddy. \\ Drafting/revision of manuscript: M. Leddy, R. Rosenheck, \\ E. Stefanovics.
}

Financial Disclosures: The authors have declared that no competing interests exist.

Funding/Support: This material was based on work supported by the Mental Health and Behavioral Sciences Service, VA Central Office, Washington, DC.

Institutional Review: IRB approval for the initial study was obtained at the authors' parent institution and at each of the nine participating VA facilities; IRB approval for this secondary analysis of the data was granted by the authors' parent institution. Veterans gave written informed consent to participate in the project and for their employment specialist to communicate with employers.

Participant Follow-Up: Human study participants will not be informed about the accepted publication.

\section{REFERENCES}

1. Rosenheck RA, Leslie D, Keefe R, McEvoy J, Swartz M, Perkins D, Stroup S, Hsiao JK, Lieberman J; CATIE Study
Investigators Group. Barriers to employment for people with schizophrenia. Am J Psychiatry. 2006;163(3):411-17. [PMID:16513861]

http://dx.doi.org/10.1176/appi.ajp.163.3.411

2. Salkever DS, Karakus MC, Slade EP, Harding CM, Hough RL, Rosenheck RA, Swartz MS, Barrio C, Yamada AM. Measures and predictors of community-based employment and earnings of persons with schizophrenia in a multisite study. Psychiatr Serv. 2007;58(3):315-24. [PMID:17325103] http://dx.doi.org/10.1176/appi.ps.58.3.315

3. Bond GR, Drake RE. Making the case for IPS supported employment. Admin Pol Ment Health Ment Health Serv Res. 2014;41(1):69-73.

4. Bond GR, Drake RE, Becker DR, Mueser KT. Effectiveness of psychiatric rehabilitation approaches for employment of people with severe mental illness. J Disab Pol Stud. 1999;10:18-52.

5. Strauss JS, Harding CM, Silberman M, Eichler A, Lieberman M. Work as treatment for psychiatric disorders: A puzzle in pieces. In: Ciardiello JA, Bell MD, editors. Vocational rehabilitation of persons with prolonged psychiatric disorders. Baltimore (MD): Johns Hopkins Press; 1988. p. 47-55.

6. Tapia DM, Castro WL, Aguilera JM. Employability strategies in population with mental disabilities: A review. Salud Ment. 2013;36:143-48.

7. Becker DR, Whitley R, Bailey EL, Drake RE. Long-term employment trajectories among participants with severe mental illness in supported employment. Psychiatr Serv. 2007;58:922-28. [PMID:17602007] http://dx.doi.org/10.1176/appi.ps.58.7.922

8. Resnick SG, Kaczynski R, Sieffert D, Baldino R, Showalter D, Gray S, et al. Fifteenth progress report on the Compensated Work Therapy (CWT) program, fiscal year 2011. West Haven (CT): Department of Veterans Affairs Northeast Program Evaluation Center; 2011.

9. Kashner TM, Rosenheck RA, Campinell AB, Surís A, Crandall R, Garfield NJ, Lapuc P, Pyrcz K, Soyka T, Wicker A. Impact of work therapy on health status among homeless, substance-dependent veterans: A randomized controlled trial. Arch Gen Psychiatry. 2002;59(10):938-44. [PMID:12365881] http://dx.doi.org/10.1001/archpsyc.59.10.938

10. Rosenheck RA, Seibyl CL. Participation and outcome in a residential treatment and work therapy program for addictive disorders: the effects of race. Am J Psychiatry. 1998; 155(8):1029-34. [PMID:9699689]

11. Veterans Health Care, Capital Asset, and Business Improvement Act of 2003, Pub. L. 108-170, 117 Stat. 2042 (Dec, 6, 2003).

12. Cook JA, Leff HS, Blyler CR, Gold PB, Goldberg RW, Mueser KT, Toprac MG, McFarlane WR, Shafer MS, Blankertz LE, Dudek K, Razzano LA, Grey DD, Burke-Miller J. 
Results of a multisite randomized trial of supported employment interventions for individuals with severe mental illness. Arch Gen Psychiatry. 2005;62(5): 505-12. [PMID:15867103] http://dx.doi.org/10.1001/archpsyc.62.5.505

13. Crowther RE, Marshall M, Bond GR, Huxley P. Helping people with severe mental illness to obtain work: Systematic review. BMJ. 2001;322(7280):204-8.

[PMID:11159616] http://dx.doi.org/10.1136/bmj.322.7280.204

14. Killackey EJ, Jackson HJ, Gleeson J, Hickie IB, McGorry PD. Exciting career opportunity beckons! Early intervention and vocational rehabilitation in first-episode psychosis: Employing cautious optimism. Aust N Z J Psychiatry. 2006;40(11-12):951-62. [PMID:17054563] http://dx.doi.org/10.1080/j.1440-1614.2006.01918.x

15. Lehman AF. Vocational rehabilitation in schizophrenia. Schizophr Bull. 1995;21(4):645-56. [PMID:8749891] http://dx.doi.org/10.1093/schbul/21.4.645

16. Bond GR. Supported employment: Evidence for an evidence-based practice. Psychiatr Rehabil J. 2004;27(4):34559. [PMID:15222147] http://dx.doi.org/10.2975/27.2004.345.359

17. Becker DR, Drake RE. A working life for people with severe mental illness. New York (NY): Oxford University Press; 2003.

18. Bond GR, Drake RE, Becker DR. Generalizability of the Individual Placement and Support (IPS) model of supported employment outside the US. World Psychiatry. 2012;11(1):32-39. [PMID:22295007] http://dx.doi.org/10.1016/j.wpsyc.2012.01.005

19. Drake RE, Bond GR, Becker DR. IPS supported employment: An evidence-based approach to supported employment. New York (NY): Oxford University Press; 2012.

20. Burns T, Catty J, White S, Becker T, Koletsi M, Fioritti A, Rössler W, Tomov T, van Busschbach J, Wiersma D, Lauber C; EQOLISE Group. The impact of supported employment and working on clinical and social functioning: Results of an international study of individual placement and support. Schizophr Bull. 2009;35(5):949-58.

[PMID:18403375] http://dx.doi.org/10.1093/schbul/sbn024

21. Dixon LB, Dickerson F, Bellack AS, Bennett M, Dickinson D, Goldberg RW, Lehman A, Tenhula WN, Calmes C, Pasillas RM, Peer J, Kreyenbuhl J; Schizophrenia Patient Outcomes Research Team (PORT). The 2009 schizophrenia PORT psychosocial treatment recommendations and summary statements. Schizophr Bull. 2010;36(1):48-70.

[PMID:19955389]

http://dx.doi.org/10.1093/schbul/sbp115

22. Twamley EW, Jeste DV, Lehman AF. Vocational rehabilitation in schizophrenia and other psychotic disorders: A liter- ature review and meta-analysis of randomized controlled trials. J Nerv Ment Dis. 2003;191(8):515-23.

[PMID:12972854]

http://dx.doi.org/10.1097/01.nmd.0000082213.42509.69

23. Bond GR, Campbell K, Drake RE. Standardizing measures in four domains of employment outcomes for individual placement and support. Psychiatr Serv. 2012;63(8):751-57. [PMID:22660524]

http://dx.doi.org/10.1176/appi.ps.201100270

24. Lehman AF, Goldberg R, Dixon LB, McNary S, Postrado L, Hackman A, McDonnell K. Improving employment outcomes for persons with severe mental illnesses. Arch Gen Psychiatry. 2002;59(2):165-72. [PMID:11825138]

http://dx.doi.org/10.1001/archpsyc.59.2.165

25. Twamley EW, Narvaez JM, Becker DR, Bartels SJ, Jeste DV. Supported employment for middle-aged and older people with schizophrenia. Am J Psychiatr Rehabil. 2008;11(1):76-89. [PMID:19212460] http://dx.doi.org/10.1080/15487760701853326

26. Bond GR, Drake RE, Becker DR. An update on randomized controlled trials of evidence-based supported employment. Psychiatr Rehabil J. 2008;31(4):280-90.

[PMID:18407876]

http://dx.doi.org/10.2975/31.4.2008.280.290

27. Davis LL, Leon AC, Toscano R, Drebing CE, Ward LC, Parker PE, Kashner TM, Drake RE. A randomized controlled trial of supported employment among veterans with posttraumatic stress disorder. Psychiatr Serv. 2012;63(5):46470. [PMID:22307881] http://dx.doi.org/10.1176/appi.ps.201100340

28. Becker DR, Smith J, Tanzman B, Drake RE, Tremblay T. Fidelity of supported employment programs and employment outcomes. Psychiatr Serv. 2001;52(6):834-36.

[PMID:11376236]

http://dx.doi.org/10.1176/appi.ps.52.6.834

29. Bond GR, Becker DR, Drake RE. Measurement of fidelity of implementation of evidence-based practices: Case example of the IPS Fidelity Scale. Clin Psychol Sci Pract. 2011;18:126-41.

http://dx.doi.org/10.1111/j.1468-2850.2011.01244.x

30. Bond GR, Peterson AE, Becker DR, Drake RE. Validation of the Revised Individual Placement and Support Fidelity Scale (IPS-25). Psychiatr Serv. 2012;63(8):758-63.

[PMID:22660842]

http://dx.doi.org/10.1176/appi.ps.201100476

31. Bond GR, Resnick SG, Drake RE, Xie H, McHugo GJ, Bebout RR. Does competitive employment improve nonvocational outcomes for people with severe mental illness? J Consult Clin Psychol. 2001;69(3):489-501. [PMID:11495178] http://dx.doi.org/10.1037/0022-006X.69.3.489 
32. Kukla M, Bond GR, Xie H. A prospective investigation of work and nonvocational outcomes in adults with severe mental illness. J Nerv Ment Dis. 2012;200(3):214-22. [PMID:22373758] http://dx.doi.org/10.1097/NMD.0b013e318247cb29

33. Mueser KT, Becker DR, Torrey WC, Xie H, Bond GR, Drake RE, Dain BJ. Work and nonvocational domains of functioning in persons with severe mental illness: A longitudinal analysis. J Nerv Ment Dis. 1997;185(7):419-26. [PMID:9240359] http://dx.doi.org/10.1097/00005053-199707000-00001

34. Salyers MP, Becker DR, Drake RE, Torrey WC, Wyzik PF. A ten-year follow-up of a supported employment program. Psychiatr Serv. 2004;55(3):302-8. [PMID:15001732] http://dx.doi.org/10.1176/appi.ps.55.3.302

35. Drake RE, McHugo GJ, Becker DR, Anthony WA, Clark RE. The New Hampshire study of supported employment for people with severe mental illness. J Consult Clin Psychol. 1996;64(2):391-99. [PMID:8871423]

http://dx.doi.org/10.1037/0022-006X.64.2.391

36. Drake RE, McHugo GJ, Bebout RR, Becker DR, Harris M, Bond GR, Quimby E. A randomized clinical trial of supported employment for inner-city patients with severe mental disorders. Arch Gen Psychiatry. 1999;56(7):627-33. [PMID:10401508] http://dx.doi.org/10.1001/archpsyc.56.7.627

37. Mueser KT, Clark RE, Haines M, Drake RE, McHugo GJ, Bond GR, Essock SM, Becker DR, Wolfe R, Swain K. The Hartford study of supported employment for persons with severe mental illness. J Consult Clin Psychol. 2004;72(3): 479-90. [PMID:15279531] http://dx.doi.org/10.1037/0022-006X.72.3.479

38. Kukla M, Bond GR. A randomized controlled trial of evidence-based supported employment: Nonvocational outcomes. J Vocat Rehabil. 2013;38:91-98.

39. Gold PB, Meisler N, Santos AB, Carnemolla MA, Williams $\mathrm{OH}$, Keleher J. Randomized trial of supported employment integrated with assertive community treatment for rural adults with severe mental illness. Schizophr Bull. 2006;32(2):378-95. [PMID:16177278] http://dx.doi.org/10.1093/schbul/sbi056

40. Heslin M, Howard L, Leese M, McCrone P, Rice C, Jarrett M, Spokes T, Huxley P, Thornicroft G. Randomized controlled trial of supported employment in England: 2 year follow-up of the Supported Work and Needs (SWAN) study. World Psychiatry. 2011;10(2):132-37.

[PMID:21633690]

41. Hoffmann H, Jäckel D, Glauser S, Kupper Z. A randomised controlled trial of the efficacy of supported employment. Acta Psychiatr Scand. 2012;125(2):157-67. [PMID:22077907] http://dx.doi.org/10.1111/j.1600-0447.2011.01780.x
42. Latimer EA, Lecomte T, Becker DR, Drake RE, Duclos I, Piat M, Lahaie N, St-Pierre MS, Therrien C, Xie H. Generalisability of the individual placement and support model of supported employment: Results of a Canadian randomised controlled trial. Br J Psychiatry. 2006;189:65-73. [PMID:16816308] http://dx.doi.org/10.1192/bjp.bp.105.012641

43. Kilian R, Lauber C, Kalkan R, Dorn W, Rössler W, Wiersma D, van Buschbach JT, Fioritti A, Tomov T, Catty J, Burns T, Becker T. The relationships between employment, clinical status, and psychiatric hospitalisation in patients with schizophrenia receiving either IPS or a conventional vocational rehabilitation programme. Soc Psychiatry Psychiatr Epidemiol. 2012;47(9):1381-89.

[PMID:22083390]

http://dx.doi.org/10.1007/s00127-011-0451-z

44. Penk W, Drebing CE, Rosenheck RA, Krebs CA, Van Ormer A, Mueller L. Veterans Health Administration Transitional work experience vs. job placement in veterans with co-morbid substance use and non-psychotic psychiatric disorders. Psychiatr Rehabil J. 2010;33(4):297-307.

[PMID:20374988]

http://dx.doi.org/10.2975/33.4.2010.297.307

45. Blow FC, Gillon L, Dornfeld M. Comprehensive national evaluation of VHA compensated work therapy. Ann Arbor (MI): Serious Mental Illness Treatment Research and Evaluation Center; 2001.

46. Koop JI, Rollins AL, Bond GR, Salyers MP, Dincin J, Kinley T, Shimon SM, Marcelle K. Development of the DPA Fidelity Scale: Using fidelity to define an existing vocational model. Psychiatr Rehabil J. 2004;28(1):16-24. [PMID:15468632] http://dx.doi.org/10.2975/28.2004.16.24

47. Bond GR, Salyers MP, Dincin J, Drake RE, Becker DR, Fraser VV, Haines M. A randomized controlled trial comparing two vocational models for persons with severe mental illness. J Consult Clin Psychol. 2007;75(6):968-82. [PMID:18085913] http://dx.doi.org/10.1037/0022-006X.75.6.968

48. Fraser VV, Jones AM, Frounfelker RM, Harding B, Hardin T, Bond GR. VR closure rates for two vocational models. Psychiatr Rehabil J. 2008;31(4):332-39. [PMID:18407883] http://dx.doi.org/10.2975/31.4.2008.332.339

49. Rosenheck RA, Mares AS. Implementation of supported employment for homeless veterans with psychiatric or addiction disorders: Two-year outcomes. Psychiatr Serv. 2007;58(3):325-33. [PMID:17325104] http://dx.doi.org/10.1176/appi.ps.58.3.325

50. Derogatis LR. Brief Symptom Inventory (BSI) administration, scoring, and procedures manual. 3rd ed. Minneapolis (MN): National Computer Systems; 2000. 
51. McLellan AT, Luborsky L, Woody GE, O’Brien CP. An improved diagnostic evaluation instrument for substance abuse patients. The Addiction Severity Index. J Nerv Ment Dis. 1980;168(1):26-33. [PMID:7351540] http://dx.doi.org/10.1097/00005053-198001000-00006

52. Gandek B, Ware JE, Aaronson NK, Apolone G, Bjorner JB, Brazier JE, et al. Cross-validation of item selection and scoring for the SF-12 Health Survey in nine countries: Results from the International Quality of Life Assessment Project. J Clin Epidemiol. 1998;51:1171-78. [PMID:9817135] http://dx.doi.org/10.1016/S0895-4356(98)00109-7

53. Kornfeld R, Rupp K. The net effects of the Project NetWork return-to-work case management experiment on participant earnings, benefit receipt, and other outcomes. Soc Secur Bull. 2000;63(1):12-33. [PMID:10951687]

54. Mares AS, Rosenheck RA. Attitudes towards employment and employment outcomes among homeless veterans with psychiatric and substance abuse problems. Am J Psychiatr Rehabil. 2006;9:145-66. http://dx.doi.org/10.1080/15487760600961451

55. Rosenberg M. Conceiving the self. New York (NY): Basic Books; 1979.

56. Lehman AF. A quality of life interview for the chronically mentally ill. Eval Program Plann. 1988;11:51-62. http://dx.doi.org/10.1016/0149-7189(88)90033-X

57. Baron RC, Salzer MS. Accounting for unemployment among people with mental illness. Behav Sci Law. 2002; 20(6):585-99. [PMID:12465129] http://dx.doi.org/10.1002/bs1.513

58. Schur LA. Barriers or opportunities? The causes of contingent and part-time work among people with disabilities. Ind Relat. 2003;42:589-622. http://dx.doi.org/10.1111/1468-232X.00308
59. Tsai J, Rosenheck RA. Examination of Veterans Affairs disability compensation as a disincentive for employment in a population-based sample of Veterans under age 65. J Occup Rehabil. 2013;23(4):504-12. [PMID:23358807] http://dx.doi.org/10.1007/s10926-013-9419-z

60. McHugo GJ, Drake RE, Xie H, Bond GR. A 10-year study of steady employment and non-vocational outcomes among people with serious mental illness and co-occurring substance use disorders. Schizophr Res. 2012;138(2-3): 233-39. [PMID:22546432] http://dx.doi.org/10.1016/j.schres.2012.04.007

61. Mueser KT, Campbell K, Drake RE. The effectiveness of supported employment in people with dual disorders. J Dual Diagn. 2011;7(1-2):90-102. [PMID:23275763] http://dx.doi.org/10.1080/15504263.2011.568360

62. Bond GR. Modest implementation efforts, modest fidelity, and modest outcomes. Psychiatr Serv. 2007;58(3):334. [PMID:17325105] http://dx.doi.org/10.1176/appi.ps.58.3.334

Submitted for publication January 14, 2013. Accepted in revised form July 22, 2013.

This article and any supplementary material should be cited as follows:

Leddy M, Stefanovics E, Rosenheck R. Health and wellbeing of homeless veterans participating in transitional and supported employment: Six-month outcomes. J Rehabil Res Dev. 2014;51(1):161-74.

http://dx.doi.org/10.1682/JRRD.2013.01.0011

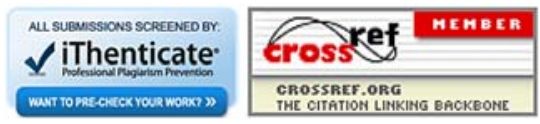


174

JRRD, Volume 51, Number 1, 2014 
